\title{
Opção pelo curso técnico integrado ao médio: os agentes influenciadores e a opinião dos estudantes
}

\section{The option for the technical-professional schooling: influencing agents and students' opinion} Opción por el curso técnico integrado a la enseñanza media: agentes influyentes y opinión de estudiantes

\author{
Nonato Assis de Miranda ${ }^{1}$ \\ Piagetti Júnior Pires Arcy²
}

DOI: http://dx.doi.org/10.20435/serie-estudos.v0i0.1310

\begin{abstract}
Resumo: O objetivo desta pesquisa foi identificar, devido ao reduzido número de estudos sobre escolha profissional para alunos que estão terminando o Ensino Fundamental, quais são os principais influenciadores na escolha pelo ensino médio na modalidade técnica, como também pela formação profissional (curso), e em que ordem de importância esses influenciadores se posicionam. Essas duas escolhas podem não compartilhar dos mesmos fatores influenciadores e nas mesmas ordens de importância, sendo nessa diferença que este estudo está fundamentado. Trata-se de uma pesquisa exploratória de natureza quali-quantitativa, realizada com adolescentes do Ensino Técnico Integrado ao Médio (Etim), cujos resultados mostram que existem diferentes motivos para escolher entre uma formação de ensino médio na modalidade técnica e o curso.
\end{abstract}

Palavras-chave: Ensino Técnico Integrado ao Médio (Etim); escolha profissional; orientação profissional.

\begin{abstract}
This research aimed to identify, due to the small number of studies on professional choice for students who are finishing Primary School, what are the main influencers in the choice of high school in the technical modality, as well as the professional training (course), and in what order of importance these influencers position themselves. These two choices may not share the same influencing factors and in the same order of importance, and this research based on this difference. It is an exploratory research of a qualitative and quantitative nature, carried out with adolescents from the Integrated Technical Education to the High School (Etim), whose results show that there are different reasons to choose between a high school education in the technical modality and the course.
\end{abstract}

Keywords: Integrated Technical Education to the High School (Etim); professional choice; professional orientation.

\footnotetext{
1 Universidade Municipal de São Caetano do Sul (Uscs). São Caetano do Sul, São Paulo, Brasil.

2 Escola Técnica Estadual Jorge Street (Etec Jorge Street). São Caetano do Sul, São Paulo, Brasil.
} 
Resumen: El objetivo de esta investigación fue identificar, debido al pequeño número de estudios sobre elección profesional para estudiantes que están terminando la escuela primaria, cuáles son los principales influyentes en la elección de la escuela secundaria en la modalidad técnica, así como de la formación profesional (curso), y en qué orden de importancia se posicionan estos influenciadores. Es posible que estas dos opciones no compartan los mismos factores de influencia y órdenes de importancia, y este estudio se basa en esta diferencia. Esta es una investigación exploratoria de naturaleza cualitativa y cuantitativa, realizada con adolescentes de la Educación Técnica Integrada a la Enseñanza Media (Etim), cuyos resultados muestran que hay diferentes razones para elegir entre una educación secundaria en la modalidad técnica y el curso.

Palabras clave: Educación Técnica Integrada a la Enseñanza Media (Etim); elección profesional; orientación profesional.

\section{INTRODUÇÃO}

A formação Técnica de Nível Médio está fundamentada em uma história de construção que visava atender as classes menos favorecidas economicamente, assim como um estudo-fim, ou seja, aquele em que está imbuído o fim em si mesmo. Diferentemente dessa modalidade de formação, a formação propedêutica procurava atender uma parcela da sociedade economicamente mais favorecida, a fim de possibilitar-lhe prosseguimento no nível superior. Trata-se, portanto, de um modelo de educação de caráter dual que esteve normatizado por legislação federal até o ano de 2004.

A partir de então, surgiu no Brasil uma nova proposta para a oferta de cursos de Nível Médio, denominada Educação Profissional Técnica de Nível Médio Integrada ao Ensino Médio (Etim), a qual é "[...] oferecida somente a quem já tenha concluído o Ensino Fundamental, sendo o curso planejado de modo a conduzir o aluno à habilitação profissional técnica de nível médio, na mesma instituição de ensino, contando com a matrícula única para cada aluno" (BRASIL, 2004). Essa nova organização permite aos estudantes cursarem, concomitantemente, componentes curriculares da base nacional comum e outras que são específicas da formação profissional, chamadas disciplinas técnicas. Desse modo, o Etim passou a ter de atender à demanda de oferecer uma formação básica e técnica simultaneamente, com vistas a acabar com o "conflito existente em torno do papel da escola, de formar para a cidadania ou para o trabalho produtivo [...]" (RAMOS, 2005, p. 106).

Essa mudança representou um grande avanço para essa modalidade de ensino, pois a formação profissional, desde as suas origens, sempre foi reservada às classes menos favorecidas, estabelecendo-se uma nítida distinção entre 
aqueles que detinham o saber (ensino secundário, normal e superior) e os que executavam tarefas manuais (ensino profissional) (BRASIL, 1999). Com a modernização do sistema industrial a partir das máquinas a vapor e das novas formas de administração científica de Taylor e da teoria clássica de Fayol, começou-se a exigir melhores qualificações da mão de obra, porém a ligação trabalho com escravidão ainda era fator marcante, desmotivando a procura pela educação voltada apenas ao trabalho, que era desvantajosa em relação à formação superior.

Com o decorrer dos anos, essa forma de ver a formação técnica vem se modificando, pois, com a implantação de novos processos organizacionais, gerenciais e tecnológicos, exigidos pelas empresas, a necessidade de qualificação profissional tornou-se não apenas prioritária, como também passou a ser um fator de melhoria social. Conforme Severnini e Orellano (2010), essa formação consegue reduzir a probabilidade de desemprego e aumenta a renda dos egressos, confirmando que a escolha por uma formação técnica de nível médio, em vez de cursar um ensino propedêutico, traz vantagens para seus formandos, uma vez que:

As empresas passaram a exigir trabalhadores cada vez mais qualificados. À destreza manual se agregam novas competências relacionadas com a inovação, a criatividade, o trabalho em equipe e a autonomia na tomada de decisões, mediadas por novas tecnologias da informação. A estrutura rígida de ocupações altera-se. Equipamentos e instalações complexas requerem trabalhadores com níveis de educação e qualificação cada vez mais elevados. As mudanças aceleradas no sistema produtivo passam a exigir uma permanente atualização das qualificações e habilitações existentes e a identificação de novos perfis profissionais. (BRASIL, 1999, p. 7).

Somando-se a isso, Loponte (2011) destaca que os fatores eleitos pelos jovens para determinar a opção pela formação técnica envolvem a gratuidade do ensino público de qualidade, o currículo diferenciado que favorece a porta de entrada para o mercado de trabalho e a viabilização do preparo para a universidade.

Soares (2002, p. 19) aponta que "[...] escolher faz parte de qualquer pessoa [...]"; entretanto, como um jovem com 14 ou 15 anos pode fazer a escolha de um curso ou ofício? Será que um jovem que, até então, está preocupado em jogar futebol, videogame no computador e praticar seu esporte predileto está apto a fazer uma escolha profissional? Entende-se que escolha é a preferência que o jovem dá a alguma coisa que se encontra entre outras, tendo em vista que, independentemente da sua condição socioeconômica, ele terá de, no decorrer de sua vida, fazer escolhas. 
Em razão disso, a família passa a ter uma forte influência nessa escolha, não tão enfática como antigamente, mas de uma forma mais flexível e aprazível. Segundo Paim (2007), a família muitas vezes entra em atrito com as vontades e os sonhos pessoais do estudante, provocando conflitos externos entre sua escolha e as expectativas dos familiares, como também conflitos internos devido a sua falta de experiência e a sua história de vida.

A família assume também a responsabilidade quanto à imparcialidade nas orientações, pois é na adolescência que se iniciam os conflitos familiares (ANDRADE, 1997). Contudo, no estudo sobre as possíveis relações entre o estilo parental, indecisão vocacional e instabilidade de metas, Magalhães, Alvarenga e Teixeira (2012) consideram que os estilos da família influenciam na capacidade de estabelecerem-se metas e impactam a escolha profissional.

Outro fator importante e que influencia na escolha de uma profissão é o mercado de trabalho que está entrelaçado a constantes mudanças econômicas internas e externas, incluindo as novas tecnologias; os colegas também são fortes influenciadores, pois, ao falarem a mesma "língua", conseguem, muitas vezes, influenciar mais do que a família e, em alguns casos, impor valores e comportamentos. Além disso, há aqueles que, por motivos socioeconômicos, necessitam de uma inserção profissional rápida, algo relatado também por Martins e Noronha (2010) em sua pesquisa. Essas autoras apontam que a condição econômica menos favorecida influi de forma direta no processo decisório; os meios de comunicação, que influenciam com suas notícias e documentários; e, por fim, o "modismo", que são os cursos mais procurados pela maioria dos jovens, o curso do momento (BOCK et al., 1995). Porém, neste estudo, foi verificado que existem diferenças quanto às influências diretas entre escolher uma escola na modalidade técnica e escolher um determinado curso.

Valore (2008) entende que escolher uma profissão é um momento de crise para qualquer adolescente, porque ele deve pensar no que "quer ser no futuro" e que eleger uma profissão implica "deixar de lado várias outras [...]".

Para Santos, Brandão e Maia (2015), a decisão profissional é feita em um ambiente incerto, com poucas informações e por pessoas inexperientes no mercado de trabalho. Já de acordo com Jordani et al. (2014), com os avanços tecnológicos, o mundo das profissões tornou-se extenso, gerando dúvidas na escolha de uma carreira a seguir, principalmente porque essa decisão ocorre em um período de grandes mudanças na vida de um adolescente. 
O excesso de informações leva o jovem a ter muitas dúvidas quanto a sua formação profissional, acrescidas da participação da família, que pode ajudar ou dificultar nessa escolha, aumentando a sensação de dúvida e insegurança. Diante dessa realidade, a escola, juntamente da orientação profissional, pode exercer influência, de forma positiva, nesse processo de decisão (LEMOS, 2001).

Segundo Jordani et al. (2014), o crescimento tecnológico gera dúvidas na escolha de uma profissão e, como esses jovens estão em um período de adolescência, de grandes mudanças, a procura por uma orientação profissional vem auxiliar nesse processo de decisão, por sanar as dificuldades da escolha e evitar que ela seja feita por impulso, sem reflexão ou, até mesmo, sem autonomia (ALVIM; MENIN, 2012, p. 235). Geralmente, a procura por uma orientação profissional, nessa idade, ainda não é vislumbrada como algo a ser feito na construção do futuro, mas vários estudiosos voltados à análise desse tema procuram definir métodos para auxiliar o adolescente a fazer a escolha mais apropriada ao seu perfil.

Pode-se pensar que, na fase de conclusão do Ensino Fundamental, o jovem se depara com a opção por uma escola técnica integrada ao Ensino Médio. Assim sendo, nessa etapa da vida, é importante que a orientação profissional tenha início no último ano do Ensino Fundamental, de modo a possibilitar a esse jovem o contato com profissões, a fim de que ele tenha subsídio para optar entre Ensino Médio tradicional (propedêutico) e técnico profissionalizante (técnico integrado ao Ensino Médio), iniciando, dessa forma, o seu projeto profissional.

Além disso, como exemplo, optar por cursar uma escola técnica integrada ao Ensino Médio, já no final do Ensino Fundamental, "[...] possibilita ao estudante optar por continuar os estudos no ensino superior, ou ingressar no mercado de trabalho, ou ainda realizar as duas atividades concomitantemente" (CINTRA, 2014, p. 22). Ademais, optar por um ensino técnico integrado ao médio permite ao aluno fazer sua primeira escolha profissional. Por conseguinte, seria assertivo se todos os alunos, no último ano do Ensino Fundamental, passassem por orientações profissionais com o objetivo de serem auxiliados quanto à escolha e, também, para minimizar angústias pessoais e reduzir evasões escolares.

Outra vantagem dessa opção de ensino técnico integrado ao médio é que o jovem poderá conhecer as possibilidades de inserção profissional com o curso escolhido a priori, como também conhecer outras formações, auxiliando-o em suas decisões caso prossiga nos estudos em nível superior. Para Cintra (2014, p. 
18), a formação técnica integrada ao Ensino Médio não é somente uma "escolha escolar, mas também profissional" e que "incorpora variáveis como a família, a escola e o mercado de trabalho".

Muitos alunos do Etim, em 2018, preferiam um curso que estava na mídia ou em destaque profissional, ou ainda cediam a pressões da família ou dos pares, fazendo da escola, ao acaso, seu laboratório vocacional. É importante pontuar que a família sempre teve uma relação muito forte com o trabalho, e esse perfil é, em muitos casos, transmitido de pais para filhos, sem questionamento (ALMEIDA; MAGALHÃES, 2011).

Para Bock (1995), se a escolha da profissão não está entre as ocupações tradicionais, a intervenção da família torna-se incisiva, forçando o jovem a indicar uma profissão que, muitas vezes, não é a pretendida. Por esse motivo, Nogueira (1998) ratifica que existe uma relação entre a história de vida dos pais e as decisões de seus filhos.

Outro dado relevante é a determinação dos pais em relação a uma profissão que "[...] realize aquilo que a família não realizou ou dar continuidade a tarefas já desenvolvidas por eles" (NEPOMUCENO; WITTER, 2010, p. 16). Nesse sentido, Almeida e Magalhães (2011) enfatizam que a orientação profissional é essencial, uma vez que auxilia o jovem a encontrar diferenças entre o que pertence ao seu desejo e o que é desejado por sua família. Assim, o significado de educação, de escola e de professor como escola têm acepções semelhantes, haja vista que a correlação entre esses substantivos é diretamente proporcional, pois, para uma boa educação acadêmica, há de terem-se boas escolas e, o mais importante, bons professores.

É importante salientar que escola é tida, também, como uma importante ferramenta na preparação para o mercado de trabalho, já que propicia conhecimentos e capacitações. Desse modo, o papel social que a instituição de ensino representa, segundo Watarai e Romanelli (2009), é a da socialização aluno-aluno e aluno-professor, por permitir uma relação útil, interativa e interdepende, oferecendo ao aluno:

Acesso a determinadas normas de conduta ausentes de seu capital cultural e que são importantes para aprenderem a se relacionar com pessoas de diferentes posições sociais e também a incorporarem conhecimento [...] sobre o mercado de trabalho. (WATARAI; ROMANELLI, 2009, p. 224). 
Nesse contexto, a escola é o local em que o jovem passa a maior parte de seu tempo, trocando informações, conhecimentos e criando uma forte fonte influenciadora no desenvolvimento de um projeto de vida (FONSECA, 1994). Além disso, para Marques e Castanho (2011), a escola é, também, um espaço que possui como função a educação e a aprendizagem dos conhecimentos formais, das artes, das ciências e da tecnologia, sob a direção de professores. Isso ressalta que a escola é um importante formador de caráter, desenvolvedor de comunicação, trocador de experiências e respeito; além disso, o professor pode ser "[...] um espelho para os alunos que o tomariam como exemplo a ser seguido" (CINTRA, 2014, p. 83).

Escutar outras pessoas e seus pontos de vista também faz parte da vida do adolescente, pois abre um leque de conhecimentos, por mais que a decisão já tenha sido tomada. Esse é um momento rico, porque o jovem começa a buscar apoio dentro e fora de seu berço familiar. Além disso, para alguns jovens, cujos vínculos familiares sofreram mudanças, o afunilamento das relações com os seus pares pode influenciar o grupo, assim como o grupo pode ser influenciado por eles (PEREIRA; GARCIA, 2007). A participação de amigos/pares não é um tema muito abordado em pesquisas e artigos de autores brasileiros; no entanto, Pereira e Garcia (2007) revelam, em suas pesquisas, que o processo de cooperação é mais expressivo do que o de influência para a escolha profissional. Assim, o objetivo desta pesquisa é conhecer os agentes influenciadores e a opinião dos estudantes quanto à opção pelo curso técnico integrado ao médio.

\section{MÉTODO}

\subsection{Procedimentos metodológicos}

Para dar conta dos objetivos desta pesquisa, foram realizados três procedimentos para a coleta de dados complementares entre si.

Inicialmente, na fase exploratória, que é utilizada quando existe a necessidade de se ter mais "[...] familiaridade com o problema, com vistas a torná-lo mais explícito ou a construir hipóteses" (GERHARDT; SILVEIRA, 2009, p. 35), foram selecionados aleatoriamente oito estudantes para participarem, individualmente, de uma entrevista com duração de 50 a 60 minutos, visando entender suas opiniões e pontos de atenção, para servir de orientação à elaboração do questionário. 
Esses alunos cursavam as modalidades em estudo (Mecânica, Mecatrônica e Automação) em diferentes séries, cursos, sexo e idade.

Em seguida, com os resultados dessas entrevistas, foi elaborado o questionário para a coleta de dados. Isso foi importante porque as dúvidas dos participantes quanto à clareza e à facilidade de compreensão das perguntas, como também outros dados que não haviam sido observados e que se revelaram durante as conversas, puderam ser acrescentados e mais bem redigidos no questionário. Esse questionário foi composto por conjuntos de assertivas que deveriam ser respondidas por meio de uma escala Likert, escolhendo o grau de importância em uma escala de 10 itens, desde concordo plenamente até discordo plenamente.

A terceira e última fase constituiu-se da aplicação do questionário em si, composto por três blocos, a saber: a) características do entrevistado; b) ensino profissional; c) escolha do curso. Todas as perguntas foram divididas por grau de concordância dentro de uma escala tipo Likert, desde discordo totalmente até concordo totalmente.

\subsection{Análise dos dados}

Após a coleta de dados, as questões de múltipla escolha e de Escala Likert foram transcritas para uma planilha eletrônica ou para o próprio programa estatístico (IBM-SPSS) que foi utilizado para tratamento dos dados na perspectiva da Análise Fatorial (AF), a qual é utilizada para investigar os padrões ou relações latentes a um número grande de variáveis e para determinar se a informação pode ser resumida a um conjunto menor de fatores (MATOS; RODRIGUES, 2019).

Por meio da AF, é possível reduzir o número de dimensões necessárias para se descrever dados derivados de um grande número de medidas (FIGUEIREDO FILHO; SILVA JÚNIOR, 2010). O fator pode ser definido como uma combinação linear das variáveis originais. Os fatores representam as dimensões latentes (construtos) que resumem o conjunto original de variáveis, mantendo a representatividade das características das variáveis originais. Assim, a AF é usada para investigar as relações entre um grande número de variáveis e organizá-las em um conjunto menor de fatores (HAIR et al., 2009). Deste modo, "os dois principais usos da análise fatorial são resumo e redução dos dados, que podem ser muito úteis à medida que o número de variáveis utilizadas em técnicas multivariadas aumenta" (MATOS; RODRIGUES, 2019, p. 9). 
Assim, as respostas de cada item foram escritas numérica e graficamente a fim de se identificar e/ou corrigir erros de digitação, de respostas atípicas, de dados omissos (itens não respondidos) e homogeneidade da variância. Os elementos obtidos desses retornos foram ponderados por AF, mais precisamente, a Análise de Componentes Principais (ACP). Com essa técnica, dados subjacentes podem ser identificados, revelando novas variáveis, porém em número inferior ao número de variáveis inicial, sem perder a significância da informação.

Ademais, essa técnica procura definir, portanto, em estudo com muitas opções, conjuntos de variáveis altamente correlacionadas, conhecidas como fatores, que, segundo Zeller e Carmines (1980), facilitam a interpretação dos dados levantados e suas inter-relações, promovendo uma melhor explanação final. Com isso, é possível a identificação de agrupamentos em um questionário (RABELO; TRÓCCOLLI; ROCHA, 2015, p.14), podendo as correlações para um conjunto de itens demonstrar se eles estão medindo a mesma dimensão da variável de interesse. É importante salientar que é mais proveitoso resumir os dados desses itens em um índice único que represente essa dimensão (FIGUEIREDO FILHO; SILVA JÚNIOR, 2010).

Para a avaliação das correlações, a AF sintetiza padrões de correlações entre os itens, podendo ser positiva quando a mudança de uma variável está associada à mudança sistemática em outra variável; caso contrário, quando o aumento de uma variável é acompanhado pela diminuição da outra, a associação é dita negativa; e, quando a correlação não é nem positiva nem negativa, possui ausência de correlação. Essa correlação entre fatores, conhecida como carga fatorial, indica, em porcentagem, a quantidade de covariância existente entre o fator e o item (LAROS, 2012, p. 185), variando de-1,00 e +1,00, sendo zero a ausência total de covariância.

Geralmente, as cargas fatoriais são significativas em uma análise exploratória, quando excedem o valor absoluto 0,30, mínimo para ser representativo do fator (LAROS, 2012). Contudo, Tabachnick e Fidell (1996) consideram o valor 0,32 como valor mínimo para conceber o item como representante da variável, pois esse valor corresponde a $10 \%$ da variância explicada $(0,32)^{2}=0,10$.

Quanto mais alta for essa variância, melhor a variável representa o fator. Nesse sentido, Comrey e Lee (1992) asseveram que cargas maiores que 0,71 são representações excelentes dessa correlação, maiores que 0,63 são muito boas, 
maiores que 0,55 são consideradas boas, maiores que 0,45 são consideradas razoáveis e maiores que 0,32 são consideradas pobres. Caso a carga fatorial não seja alta em nenhum dos fatores, a variável deve ser excluída e a análise fatorial deveria ser refeita com o subconjunto restante de itens.

Quanto ao tamanho da amostra, ao se utilizar uma análise fatorial, os melhores resultados são obtidos com amostras heterogêneas (LAROS, 2012). É definida por Crocker e Algina (1986) uma amostra mínima de 10 pessoas por variável, com um mínimo de 100 pessoas na amostra total. Em síntese, os parâmetros utilizados na AF podem ser assim compreendidos (Quadro 1):

Quadro 1-Síntese de critério para análise fatorial

\begin{tabular}{|c|l|}
\hline Nível de mensuração & \multicolumn{1}{|c|}{ Variáveis contínuas e discretas } \\
\hline Amostra & $\begin{array}{l}\text { Amostras mínimas entre } 50 \text { e } 100 \text { casos; razão } \\
\text { entre o número de observações e a quantidade de } \\
\text { variáveis igual ou superior a cinco. }\end{array}$ \\
\hline Correlação & $\begin{array}{l}\text { Maior parte dos coeficientes de correlação deve } \\
\text { apresentar valores acima de 0,30. }\end{array}$ \\
\hline KMO & $\begin{array}{l}\text { Quanto maior, melhor, tendo 0,50 como o patamar } \\
\text { mínimo de adequabilidade (Hair et al., 2006). }\end{array}$ \\
\hline BTS & $p<0,05$ \\
\hline
\end{tabular}

Fonte: Adaptado pelos autores, Figueiredo Filho e Silva Júnior (2010, p. 167).

\section{APRESENTAÇÃO DE RESULTADOS}

\subsection{Características do entrevistado}

O universo desta pesquisa foi composto por 631 estudantes, dos quais 484 participaram deste estudo. Estes estavam, então, frequentando os cursos de formação: Automação, Mecânica e Mecatrônica, das duas escolas pesquisadas, sendo 227 estudantes da Etec Getúlio Vargas e 257 estudantes da Etec Jorge Street.

Quanto ao gênero, a maioria dos estudantes que fazem a escolha por um dos três cursos são do sexo masculino (87\%). Supostamente, isso se deve ao direcionamento profissional dos cursos, que é voltado à área industrial, não sendo cursos de maior interesse do sexo feminino. 


\subsection{Motivo da escolha pela modalidade técnica}

Para tratar dados quantitativamente, utilizando a análise fatorial, faz-se necessário realizar alguns procedimentos prévios, a saber: verificar a adequabilidade da base de dados; determinar a técnica de extração e o número de fatores a serem extraídos; e decidir o tipo de rotação dos fatores.

Nessa dimensão, foi realizado o teste de adequação de amostragem de Kaiser-Meyer-Olkin (KMO) - Tabela 1.

Tabela 1 - Teste de Adequação da Amostra (KMO and Bartlett's Test)

\begin{tabular}{cc}
\hline KMO & 0,807 \\
BTS & 955.239 \\
gl. & 21 \\
sig. & 0.000 \\
\hline
\end{tabular}

Fonte: Elaborada pelos autores, com base nos dados coletados do software IBM SPSS (2019).

O teste de KMO varia entre 0 e 1 , sendo que, quanto mais perto de 1 , tanto melhor. Conforme Pallant (2007), o limite razoável é 0,6; no entanto Friel (2009) sugere a seguinte escala para interpretar o valor da estatística KMO: entre 0,90 e 1, excelente; entre 0,80 e 0,89, bom; entre 0,70 e 0,79, mediano; entre 0,60 e 0,69, medíocre; entre 0,50 e 0,59, ruim; e entre 0 e 0,49, inadequado. Já Hair et al. (2009) sugerem 0,50 como patamar aceitável.

$\mathrm{O}$ valor obtido neste teste deve ser $\mathrm{KMO} \geq 0,5$ para que a ferramenta seja considerada aplicável aos dados. Nesse sentido, o resultado obtido foi de 0,807, sendo um valor maior que 0,500 , constatando-se que o método fatorial pode ser utilizado.

Em seguida, realizou-se o teste de esfericidade de Bartlett's Test of Sphericity (BTS), que deve ser estatisticamente significante $(p<0,05)$. Como o $p$-valor (sig) é menor que o nível de significância 0,05, significa admitir que a análise é adequada. Também foi observada a comunalidade por meio da Matriz de Correlações anti-imagem, visando verificar as variáveis que atrapalham a análise. Adicionalmente, com vistas a verificar as variáveis que eventualmente atrapalhariam a análise, foi observada a comunalidade por meio da Matriz de correlações anti-imagem. 
Segundo o critério de Kaiser, foram extraídos dois fatores que explicam cerca de 60,69\% da variância total dos dados (Tabela 2): o primeiro fator apresenta um eigenvalue de 3,03, carregando cerca de 43,30\% da variância total dos dados, e o segundo fator apresenta um eigenvalue de 1,217, carregando cerca de 17,38\% da variância total dos dados.

Tabela 2 - Eigenvalues e variância acumulada

\begin{tabular}{|c|c|c|c|c|c|c|c|c|c|}
\hline \multirow{2}{*}{ Componente } & \multicolumn{4}{|c|}{ Initial Eigenvalues } & \multicolumn{3}{c|}{$\begin{array}{c}\text { Extraction Sums of Squared } \\
\text { Loading }\end{array}$} & \multicolumn{2}{c|}{$\begin{array}{c}\text { Rotation Sums of Squared } \\
\text { Loadings }\end{array}$} \\
\cline { 2 - 9 } & Total & $\begin{array}{c}\% \\
\text { variância }\end{array}$ & $\begin{array}{c}\% \\
\text { acumulado }\end{array}$ & Total & $\begin{array}{c}\% \\
\text { variância }\end{array}$ & $\begin{array}{c}\% \\
\text { acumulado }\end{array}$ & Total & $\begin{array}{c}\% \\
\text { variância acumulado }\end{array}$ \\
\hline 1 & 3,031 & 43,305 & 43,305 & 3,031 & 43,305 & 43,305 & 2,994 & 42,771 & 42,771 \\
\hline 2 & 1,217 & 17,386 & 60,691 & 1,217 & 17,386 & 60,691 & 1,254 & 17,920 & 60,691 \\
\hline
\end{tabular}

Fonte: Elaborada pelos autores, com base nos dados coletados do software IBM SPSS (2019).

Tanto Hair et al. (2009) quanto Schawb (2007) sugerem que a extração deve continuar até serem captados pelo menos $60 \%$ das variâncias, o que foi atendido pelas extrações realizadas.

A seguir, foi realizada a "rotação dos fatores" (Tab. 3), que é um processo de rotação capaz de transformar a complexa estrutura de correlação das variáveis em uma estrutura mais simples para interpretação dos fatores. Aplicou-se, então, o método de rotação Varimax, visando obter uma clara separação entre os fatores, mas preservando a sua orientação original.

Tabela 3 - Matriz rotacionada (Varimax)

\begin{tabular}{|l|c|c|}
\hline \multirow{2}{*}{} & \multicolumn{2}{|c|}{ Componente } \\
\cline { 2 - 3 } & $\mathbf{1}$ & $\mathbf{2}$ \\
\hline $\begin{array}{l}\text { Escolhi o Etim porque terei mais chances de inserção no mercado } \\
\text { de trabalho, a qualquer tempo. }\end{array}$ & 0,825 & $-0,010$ \\
\hline $\begin{array}{l}\text { Escolhi o Etim porque a formação teórica e prática garantem ao } \\
\text { profissional acesso ao mercado de trabalho, com maior facilidade. }\end{array}$ & 0,820 & 0,000 \\
\hline $\begin{array}{l}\text { Escolhi o Etim porque as empresas dão preferência para } \\
\text { profissionais com essa formação. }\end{array}$ & 0,817 & $-0,054$ \\
\hline $\begin{array}{l}\text { Escolhi o Etim porque em tempos de crise, com essa formação, } \\
\text { aumentam as chances de se obter um emprego. }\end{array}$ & 0,795 & 0,121 \\
\hline
\end{tabular}




\begin{tabular}{|l|c|c|}
\hline \multirow{2}{*}{} & \multicolumn{2}{|c|}{ Componente } \\
\cline { 2 - 3 } & $\mathbf{1}$ & $\mathbf{2}$ \\
\hline $\begin{array}{l}\text { Escolhi o Etim porque, além da formação profissional, esse curso } \\
\text { garante o prosseguimento de estudos em nível superior. }\end{array}$ & 0,581 & 0,257 \\
\hline $\begin{array}{l}\text { Escolhi o Etim porque meus professores me incentivaram a } \\
\text { procurar essa formação. }\end{array}$ & 0,054 & 0,785 \\
\hline Escolhi o Etim porque obtive recomendações de amigos. & 0,029 & 0,745 \\
\hline
\end{tabular}

Fonte: Elaborada pelos autores, com base nos dados coletados do software IBM SPSS (2019).

Como regras práticas, a carga fatorial mínima significante é 0,30 . Cargas em 0,40 são consideradas mais importantes e, acima de 0,50, são consideradas significantes.

Para poder fazer uma interpretação técnica, os fatores foram agrupados por similaridade das variáveis (Tab. 4) e nomeados de acordo com a interpretação técnica dessas variáveis.

Tabela 4 - Similaridade das variáveis

\begin{tabular}{|c|c|c|c|c|c|}
\hline $\begin{array}{l}\text { Ordem } \\
\text { do fator }\end{array}$ & $\begin{array}{c}\text { Denominação } \\
\text { (variáveis } \\
\text { latentes) }\end{array}$ & Variáveis determinantes & Média & $\begin{array}{l}\text { Top } \\
\text { Box }\end{array}$ & Floor \\
\hline \multirow{4}{*}{1} & \multirow{4}{*}{$\begin{array}{l}\text { Acessibilidade } \\
\text { ao mercado } \\
\text { de trabalho e } \\
\text { nível superior }\end{array}$} & $\begin{array}{l}\text { 10b - Escolhi o Etim porque } \\
\text { terei mais chances de } \\
\text { inserção no mercado de } \\
\text { trabalho, a qualquer tempo. }\end{array}$ & 7,09 & $19,2-25,9$ & $1,5-6,3$ \\
\hline & & $\begin{array}{l}\text { 10h - Escolhi o Etim porque } \\
\text { a formação teórica e prática } \\
\text { garante ao profissional } \\
\text { acesso ao mercado de } \\
\text { trabalho, com maior } \\
\text { facilidade. }\end{array}$ & 7,18 & $1,8-26,3$ & $2,5-5,4$ \\
\hline & & $\begin{array}{l}\text { 10g - Escolhi o Etim porque } \\
\text { em tempos de crise, com } \\
\text { essa formação, aumentam } \\
\text { as chances de se obter um } \\
\text { emprego. }\end{array}$ & 6,60 & $20,7-21,4$ & $4,0-9,1$ \\
\hline & & $\begin{array}{l}\text { 10c - Escolhi o Etim porque } \\
\text { as empresas dão preferência } \\
\text { para profissionais com essa } \\
\text { formação. }\end{array}$ & 6,60 & $12,6-17,8$ & $4,0-5,4$ \\
\hline
\end{tabular}




\begin{tabular}{|c|c|c|c|c|c|}
\hline $\begin{array}{c}\text { Ordem } \\
\text { do fator }\end{array}$ & $\begin{array}{c}\text { Denominação } \\
\text { (variáveis } \\
\text { latentes) }\end{array}$ & Variáveis determinantes & Média & $\begin{array}{c}\text { Top } \\
\text { Box }\end{array}$ & Floor \\
\hline 1 & $\begin{array}{c}\text { Acessibilidade } \\
\text { ao mercado } \\
\text { de trabalho e } \\
\text { nível superior }\end{array}$ & $\begin{array}{l}\text { 10f-Escolhi o Etim } \\
\text { porque, além da formação } \\
\text { profissional, esse curso } \\
\text { garante o prosseguimento } \\
\text { de estudos em nível } \\
\text { superior. }\end{array}$ & 6,69 & $19,2-25,3$ & $5,2-12,5$ \\
\hline 2 & $\begin{array}{l}\text { 10e- Escolhi o Etim porque } \\
\text { meus professores me } \\
\text { incentivaram a procurar por } \\
\text { essa formação. }\end{array}$ & 3,56 & $4,6-12,2$ & $27,8-41,1$ \\
\hline referências & $\begin{array}{l}\text { 10d - Escolhi o Etim porque } \\
\text { obtive recomendações de } \\
\text { amigos. }\end{array}$ & 3,71 & $7,5-8,1$ & $25,8-43,8$ \\
\hline
\end{tabular}

Fonte: Elaborada pelos autores, com base nos dados coletados do software IBM SPSS (2019).

- Grupos de referência (10e, 10d): esse fator indica as referências internas e externas que formam a base para sustentar a escolha pelo ensino na modalidade técnica.

- Acessibilidade ao mercado de trabalho e ao nível superior (10b, 10h, 10g, 10c, 10f): esse fator indica o grau de importância, para os jovens, do ensino técnico em relação à inserção no mercado de trabalho.

\subsection{Motivo da escolha do curso}

Para verificar se os dados poderiam ser analisados pelo método de análise fatorial, foi realizado o teste KMO (Tab. 5).

Tabela 5 - Teste de adequação da amostra (KMO and Bartlett's Test)

\begin{tabular}{cc}
\hline KMO & 0,746 \\
BTS & 834.602 \\
dl & 36 \\
sig. & 0.000 \\
\hline
\end{tabular}

Fonte: Elaborada pelos autores, com base nos dados coletados do software IBM SPSS (2109). 
Foi verificado também o teste BTS, que deve ser estatisticamente significante $(p<0,05)$. Comprovou-se que existe correlação suficientemente forte para que a análise fatorial possa ser aplicada. Verificou-se, então, na matriz de comunalidade, a percentagem de variabilidade explicada de cada variável quando agrupada em fator, que deve ser sempre superior a 0,6.

Antes de extrair as variáveis, foi verificado o nível de associação entre a variável e o fator extraído, utilizando o valor da comunalidade. Esse valor é indicado na matriz de comunalidade (Tab. 6) e indica a percentagem de variabilidade explicada de cada variável quando agrupada em fator, que deve ser sempre superior a 0,5. Caso o valor esteja abaixo, a decisão deve ser tomada, pelos pesquisadores, com base na importância da referida variável ao estudo.

Tabela 6 - Análise do componente principal - método de extração

\begin{tabular}{|l|c|c|}
\hline \multicolumn{2}{|c|}{ Initial } & Extraction \\
\hline Escolhi esse curso porque tem muita familiaridade comigo. & 1,000 & 0,648 \\
\hline $\begin{array}{l}\text { Escolhi esse curso porque tenho muito interesse por essa } \\
\text { área profissional. }\end{array}$ & 1,000 & 0,728 \\
\hline $\begin{array}{l}\text { Escolhi esse curso porque é de fácil acesso (a concorrência } \\
\text { para entrar na Etec é menor). }\end{array}$ & 1,000 & 0,576 \\
\hline $\begin{array}{l}\text { Escolhi esse curso porque é abrangente, dando uma boa } \\
\text { visão de diferentes áreas. }\end{array}$ & 1,000 & 0,394 \\
\hline $\begin{array}{l}\text { Escolhi esse curso porque minha intenção é trabalhar na área } \\
\text { técnica. }\end{array}$ & 1,000 & 0,570 \\
\hline $\begin{array}{l}\text { Escolhi esse curso porque temos tradição familiar nessa área } \\
\text { profissional. }\end{array}$ & 1,000 & 0,625 \\
\hline $\begin{array}{l}\text { Escolhi esse curso porque o mercado de trabalho não está } \\
\text { saturado nessa área profissional. }\end{array}$ & 1,000 & 0,614 \\
\hline $\begin{array}{l}\text { Escolhi esse curso porque terei maiores chances de arrumar } \\
\text { um emprego na área. }\end{array}$ & 1,000 & 0,643 \\
\hline Escolhi esse curso porque tive recomendações de familiares. & 1,000 & 0,600 \\
\hline
\end{tabular}

Fonte: Elaborada pelos autores, com base nos dados coletados do software SPSS-IBM (2019).

O fator "Escolhi esse curso porque é abrangente, dando uma boa visão de diferentes áreas" apresentou valor abaixo de 0,5, porém foi decidido mantê-lo, 
para verificar se, na extração dos fatores, ele é determinante para o entendimento do motivo da escolha do curso.

Em continuidade à análise, foi realizada a "rotação dos fatores", visando transformar a complexa estrutura de correlação das variáveis em uma estrutura mais simples para interpretação dos resultados (Tab. 7). Para poder fazer a interpretação técnica dos resultados obtidos, os fatores foram agrupados por similaridade das variáveis e nomeados de acordo com a interpretação técnica dessas variáveis.

Tabela 7 - Matriz rotacionada (Varimax)

\begin{tabular}{|c|c|c|c|c|c|}
\hline & & \multirow{2}{*}{ Média } & \multicolumn{3}{|c|}{ Componente } \\
\hline & & & 1 & 2 & 3 \\
\hline \multirow{4}{*}{ Trabalho } & $\begin{array}{l}\text { 11h- Escolhi esse curso porque terei } \\
\text { maiores chances de arrumar um } \\
\text { emprego na área. }\end{array}$ & 5,69 & 0,781 & 0,100 & 0,150 \\
\hline & $\begin{array}{l}\text { 11g- Escolhi esse curso porque o } \\
\text { mercado de trabalho não está saturado } \\
\text { nessa área profissional. }\end{array}$ & 3,77 & 0,753 & $-0,183$ & 0,120 \\
\hline & $\begin{array}{l}\text { 11e- Escolhi esse curso porque minha } \\
\text { intenção é trabalhar na área técnica. }\end{array}$ & 4,96 & 0,652 & 0,357 & 0,132 \\
\hline & $\begin{array}{l}\text { 11d- Escolhi esse curso porque é } \\
\text { abrangente, dando uma boa visão de } \\
\text { diferentes áreas. }\end{array}$ & 6,70 & 0,562 & 0,251 & $-0,125$ \\
\hline \multirow{3}{*}{$\begin{array}{l}\text { Grupo de } \\
\text { interesse } \\
\text { pessoal }\end{array}$} & $\begin{array}{l}\text { 11a- Escolhi esse curso porque tem } \\
\text { muita familiaridade comigo. }\end{array}$ & 5,85 & 0,194 & 0,764 & 0,167 \\
\hline & $\begin{array}{l}\text { 11b- Escolhi esse curso porque } \\
\text { tenho muito interesse por essa área } \\
\text { profissional. }\end{array}$ & 6,36 & 0,432 & 0,729 & 0,100 \\
\hline & $\begin{array}{l}\text { 11c- Escolhi esse curso porque é de } \\
\text { fácil acesso (a concorrência para entrar } \\
\text { na Etec é menor). }\end{array}$ & 2,96 & 0,195 & $-0,660$ & 0,319 \\
\hline \multirow{2}{*}{$\begin{array}{l}\text { Grupo de } \\
\text { referência }\end{array}$} & $\begin{array}{l}\text { 11f- Escolhi esse curso porque } \\
\text { temos tradição familiar nessa área } \\
\text { profissional. }\end{array}$ & 2,29 & 0,097 & 0,038 & 0,784 \\
\hline & $\begin{array}{l}\text { 11i- Escolhi esse curso porque tive } \\
\text { recomendações de familiares. }\end{array}$ & 5,11 & 0035 & $-0,08$ & 0,774 \\
\hline
\end{tabular}

Fonte: Elaborada pelos autores, com base nos dados coletados do software IBM SPSS (2019). 
Os principais fatores agrupados por similaridade são:

- Trabalho (11h, 11g, 11e, 11d); esse fator indica o grau de importância, para os jovens pesquisados, com relação a arrumar um emprego, como também a preocupação de escolher por um curso abrangente, cuja interdisciplinaridade propicia uma visão mais abrangente de diversas áreas.

- Grupo de interesse pessoal (11a, 11b, 11c): esse fator indica o interesse que os jovens pesquisados atribuem para a escolha do curso.

- Grupo de referência (11f, 11i): esse fator indica as referências que formam a base para sustentar a escolha pelo curso técnico.

Após a extração dos três fatores - trabalho, grupo de interesse pessoal e grupo de referência -, foram verificadas as médias de cada uma das variáveis, de cada fator extraído, para conhecer o principal motivo pela escolha do curso.

Verifica-se que, no grupo trabalho, a escolha por um curso que garanta uma boa visão de diferentes áreas é o objetivo principal da escolha.

\section{ANÁLISE DOS RESULTADOS}

Os resultados mostram que houve uma divisão em duas variáveis, cuja estrutura latente impulsionou a decisão pelo ensino de nível médio na modalidade técnica, sendo elas: o mercado de trabalho $(43,3 \%)$ e a influência dos grupos de referência (17,38\%). Em conjunto, esses dados explicam 60,69\% da variância das variáveis originais, sendo o fator que mais impulsionou nessa percepção.

Um fator significante nos resultados da pesquisa foi em relação aos grupos referenciais. Pelos dados apresentados nesta pesquisa, para constatar os motivos que levaram os jovens a escolher pela modalidade técnica do ensino de nível médio em vez do ensino médio propedêutico, verifica-se que a interferência familiar deixou de ser importante nessa decisão, pois escolhas profissionais não seguem mais o projeto de vida desenhado pelos familiares. Isso ocorre em razão do surgimento de centenas de novas profissões, enquanto muitas outras deixaram de existir (ALMEIDA; MAGALHÃES, 2011).

Esse novo processo alterou a escolha da profissão e de carreira, não levando mais em conta a necessidade de seguir os passos familiares de determinadas carreiras, mas sim de procurar experimentos em outras áreas de trabalho. Isso não quer dizer que a família deixou de ser uma fonte de estímulo e orientação para o jovem, pois os pais devem preparar seus filhos para decidirem e escolhe- 
rem o que querem, não sendo determinantes na escolha da profissão (JORDANI et al, 2014).

Dois grupos se destacaram na análise fatorial, quando formuladas as perguntas para verificar o grau de concordância dos estudantes acerca do tema investigado, sendo, em primeiro lugar, os amigos (média =3,71): pergunta 10d- "Escolhi o Etim porque obtive recomendações de amigos". Isso pode ser compreendido por terem a mesma faixa de idade e por falarem "a mesma língua", conseguindo, assim, trocar mais informações com respeito a um projeto futuro. E, em segundo (média $=3,56$ ), a participação dos professores, pergunta 10e - "Escolhi o Etim porque meus professores me incentivaram a procurar por essa formação". Isso mostra que professores e escola têm um enorme papel no delineamento do projeto de vida de um jovem estudante.

Essas assertivas apresentaram um alto valor de correlação. Já, ao verificar os valores Top Box e Floor referentes às percentagens de alunos que deram nota dez e zero, respectivamente, para a pergunta afirmativa, percebe-se que a influência do professor e de amigos tem uma baixa porcentagem de concordância (4,6\% a $12,2 \%$ ) e uma alta porcentagem de discordância (17,38\% a 43,3\%). Contudo, nessa análise fatorial, ficou evidenciada uma alta correlação, entre esses fatores, quanto à escolha pelo Ensino Médio, na modalidade técnica.

É oportuno destacar que a assertiva 10a- "Escolhi o Etim por recomendação de membros da família" foi descartada da análise preliminar por apresentar todas as correlações abaixo do mínimo requerido. Um motivo observado é que, ao se compararem os resultados alcançados pelas respostas dos itens $10 \mathrm{e}$ e $10 \mathrm{~d}$, os estudantes pesquisados que pontuaram esses fatores como influenciadores, na escolha, reduziram a intensidade do seu sentimento quanto à participação da família (10a), por mais que essa questão fosse a primeira da lista de perguntas.

Outro aspecto a ser destacado é que os grupos de referência têm um papel importante sobre os adolescentes no que tange à escolha de um curso técnico, conforme sinalizam esses resultados. Contudo, se, por um lado, a família é importante; por outro, não é determinante na escolha do curso ou profissão, pois não há como descartar a influência dos amigos (SANTOS, 2005).

Em todas as respostas da pesquisa, o professor aparece como uma figura influenciadora, tanto na escolha da formação na modalidade técnica, como também na escolha do curso, ratificando sua contribuição no processo de aprendizagem 
e na formação do cidadão, bem como auxiliando o estudante com fontes e informações sobre os cursos a serem frequentados (GOMES, 2013).

O principal fator para a escolha dos cursos de Mecânica, Mecatrônica e Automação, na modalidade Etim, apontado nesta pesquisa, está associado à percepção que os jovens pesquisados atribuem às oportunidades de emprego e ao aprendizado de diversas disciplinas técnicas. Pôde-se constatar, pela resposta à pergunta $11 \mathrm{~h}$ - "Escolhi este curso porque terei maiores chances de arrumar um emprego na área", que a inserção no mercado de trabalho (emprego) continua a ser o fator principal da escolha da formação na modalidade técnica, assim como da escolha do curso pretendido. A qualificação para o mercado de trabalho visando a um emprego futuro é, portanto, uma constante no imaginário juvenil, fazendo com que o jovem busque por qualificações profissionais. Conforme Gomes (2013, p. 49), "[...] o trabalho pode assumir diferentes significados para os jovens, seja de crescimento, independência ou muitas vezes o sentido de necessidade".

Nesse grupo pesquisado, pertencente a uma classe social média e média-alta, descaracteriza-se a finalidade inicial da escolha de um curso, visando exclusivamente à iniciação profissional e que tem por finalidade uma escola técnica, que é a de atender jovens de classes sociais menos favorecidas. Contudo, com a globalização do mercado e a necessidade de profissionais técnicos (ALMEIDA; MAGALHÃES, 2011), a escolha do curso técnico deixou de ser uma exclusividade entre os jovens de classes menos favorecidas, pois os jovens das classes médias, que estão sendo chamados a escolher uma profissão e, consequentemente, procurar criar seus projetos profissionais e de vida, também têm buscado esses cursos. Dessa forma, a procura por cursos que propiciem uma visão geral de várias áreas e dos quais o mercado de trabalho ainda não esteja saturado, assim como cursos cujas atividades poderão ser exploradas com microempresas ou autônomos são os mais procurados.

Pôde-se constatar, nesta pesquisa, que o principal motivo pela escolha do curso no fator trabalho é a sua abrangência, possibilitando visão mais generalista, conforme a afirmativa 11d - "Escolhi esse curso porque é abrangente, dando uma boa visão de diferentes áreas", que obteve uma média de 6,70.

Diferentemente dos motivos da escolha do Ensino Médio na modalidade técnica (Etim), quando são verificados esses mesmos motivos visualizando a escolha do curso, o grupo de referência, agora, passa a ser fortemente influenciado pelos familiares (média $=5,11$ ) e, em seguida, pela tradição familiar, porém com 
baixa influência (média = 2,29). Ramos e Lima (1996, p. 206), em sua pesquisa na cidade do Recife, observaram que $80 \%$ dos jovens fizeram suas escolhas de acordo com os desejos de seus familiares. Em contrapartida, Jordani et al. (2014) destacam que escolher um curso que promoverá uma carreira futura, seguindo os passos tradicionais dos familiares, já não é mais algo relacionado às tradições, pois os jovens procuram por novas áreas de atuação, visando ao aprendizado contínuo como também à garantia de uma empregabilidade futura.

Para o grupo de estudantes que participaram desta pesquisa, o que se pôde observar foi que os jovens procuram o aconselhamento familiar como referência para a escolha do curso ou para continuar a tradição familiar. Será que o motivo de seguir a tradição familiar facilitaria sua empregabilidade ou a obtenção de um estágio, como pode ser observado nas apreciações de Jordani et al. (2014) e Ramos e Lima (1996)?

Para Jordani et al. (2014), a participação dos pais na ajuda pela escolha do curso é fundamental, pois, com todas as opções, os jovens ficam envoltos em dúvidas e inseguranças. Essas indecisões poderiam ser minimizadas, caso eles tivessem orientação profissional no último ano do Ensino Fundamental, o que poderia reduzir as ansiedades e expandir suas visões do mundo do trabalho para que pudessem criar seus projetos de vida. Nesta pesquisa, a recomendação familiar na escolha do curso teve uma significância de 17,3\% que, somada ao grupo "trabalho", respondeu por 48,2\% das variáveis do grupo.

\section{CONSIDERAÇÕES FINAIS}

Esta pesquisa mostra que, nos grupos pesquisados, não é a família a grande fonte influenciadora da escolha, mas sim a acessibilidade ao mercado de trabalho e ao nível superior. Além disso, amigos e professores foram apontados como suas principais fontes sugestivas, como destacado por vários pesquisadores, entre eles Almeida e Magalhães (2011), Santos, (2005), Cintra (2014) e Loponte (2011).

A acessibilidade ao mercado de trabalho e ao nível superior caracteriza uma nova forma de os jovens visualizarem como deverá ser seu preparo educacional futuro, para serem competitivos no mundo coorporativo. Assim, é necessário acompanhar o desenvolvimento tecnológico em que o mundo está se envolvendo, para preparar e qualificar as pessoas, notadamente os jovens, à inserção profissional, o que pode ser iniciado com uma formação técnica. Isso reflete num dos fatores que pode orientar a escolha de um curso técnico integrado ao médio, assim como um 
curso em nível superior, caso esses alunos queiram prosseguir na mesma linha de formação do ensino técnico. Contudo, não se pode concluir que preocupações de inserção profissional se devem às condições socioeconômicas dos participantes, impondo a necessidade de arrumar um emprego imediatamente após sua formação, pois há outros fatores que devem ser considerados neste momento.

Quanto ao grupo de interesse pessoal, a escolha pelo curso envolve não só a familiaridade com ele, mas também o interesse pela área profissional e a baixa concorrência para ingresso nas Etec em questão. Para o grupo de referência, o destaque está voltado aos critérios de escolha, envolvendo tradição familiar na área profissional escolhida, juntamente a recomendações familiares. Pode-se entender, com isso, que, na perspectiva do estudante, a entrada no mercado de trabalho pode ser facilitada quando da existência de um membro de sua família já atuando na empresa.

Observou-se, também, que a escolha por alguns cursos teve a influência de pais, de amigos e de professores, como também da mídia, deixando muitas dúvidas em relação a qual modalidade de curso o estudante deveria seguir. É nessa dúvida que se enfoca, aqui, a orientação profissional desde o fim do Ensino Fundamental, mas não uma orientação em que é aplicado um questionário para o aluno responder e, como resultado, informar-lhe as profissões com que ele teria mais afinidade, mas sim uma orientação que acompanhasse esse aluno durante seu último ano do Ensino Fundamental, com o objetivo de criar um projeto de vida e detalhar as possibilidades de cursos com a formação de Ensino Médio.

\section{REFERÊNCIAS}

ALMEIDA, M. E. G. G. D.; MAGALHÃES, A. S. Escolha profissional na contemporaneidade: projeto individual e processo familiar. Revista Brasileira de Orientação Profissional, Porto Alegre, v. 12, n. 2, p. 205-14, 2011.

ALVIM, J. L.; MENIN, M. S. S. Papel da escola na orientação profissional: uma análise contemporânea da dimensão teórica e prática na cidade de Presidente Prudente- SP. Revista Nuances: estudos sobre Educação, Presidente Prudente ano XVIII, v. 23, n. 24, p. 235-38, set./dez. 2012.

ANDRADE, T. D. A família e a estruturação ocupacional do indivíduo. In: LEVENFUS, R. S. (Org.) Psicodinâmica da escolha profissional. Porto Alegre: Artes Médicas, 1997. p. 123-134. 
BOCK, A. M. B. (Org.) A escolha profissional em questão. 2. ed. São Paulo: Casa do Psicólogo, 1995.

BRASIL. Parecer CNE/CEB n. 16, de 5 de outubro de 1999. Dispõe sobre as Diretrizes Curriculares Nacionais para a Educação Profissional de Nível Técnico. Brasília-DF, 1999.

BRASIL. Conselho Nacional de Educação e Conselho de Educação Básica. Parecer CNE/ CEB n. 39, de 8 de dezembro de 2004. Aplicação do Decreto n. 5.154/2004 na Educação Profissional Técnica de nível médio e no Ensino Médio. Brasília-DF, 2004.

CINTRA, M. S. F. A importância da família, escola e pares no processo de escolha pelo Ensino Médio Técnico. 2014. 121 f. Dissertação (Mestrado em Educação) - Faculdade de Filosofia, Ciências e Letras de Ribeirão Preto, da Universidade de São Paulo, Riberão Preto, SP, 2014.

COMREY, A. L.; LEE, H. B. A first Course in factor analysis. New Jersey: Lawrence Erlbaum Associates, 1992.

CROCKER, L. M.; ALGINA, J. Introduction to classical and modern test theory. New York: Holt, Rinehart and Winston, 1986.

FIGUEIREDO FILHO, D. B.; SILVA JÚNIOR, J. A. Visão além do alcance: uma introdução à análise fatorial. Opinião Pública, Campinas, v. 16, n. 1, p. 160-85, jun. 2010.

FONSECA, A. M. Personalidade, projectos vocacionais e formação pessoal e social. Porto: Porto Editora, 1994.

FRIEL, C. M. Notes on factor analysis. Sam Houston State University. Criminal Justice Center, 2009.

GERHARDT, T. E.; SILVEIRA, D. T. Método de Pesquisa. Porto Alegre: UFRGS, 2009. (EAD - Série Educação a Distância). Disponível em: http://www.ufrgs.br/cursopgdr/ downloadsSerie/derad005.pdf. Acesso em: 10 mar. 2019.

GOMES, J. P. Educação Profissional: as perspectivas de jovens do DF acerca de suas escolhas e expectativas futuras. 2013. 79 f. Trabalho de Conclusão de Curso (Licenciatura em Pedagogia) - Universidade de Brasília, Brasília, 2013.

HAIR, J. F.; ANDERSON, R. E.; TATHAM, R. L.; BLACK, W. C. Análise multivariada de dados. Tradução de Adonai Schlup Sant'Anna. 6. ed. Porto Alegre: Bookman, 2009. 
JORDANI, P. S.; BARICHELLO, R.; ARTMANN, C.R.; ECKER, J. S. Fatores determinantes na escolha profissional: um estudo com alunos concluintes do Ensino Médio da Região Oeste de Santa Catarina. Revista ADMpg, Ponta Grossa, v. 7, n. 2, p. 25-32, 2014.

LAROS, A. J. O uso da análise fatorial: algumas diretrizes para pesquisadores. LabPAM Saber e Tecnologia, 2012. Disponível em: https://www.researchgate.net/ publication/233735561_O_Uso_da_Analise_Fatorial_Algumas_Diretrizes_para_ Pesquisadores. Acesso em: 15 mar. 2018.

LEMOS, C. G. Adolescência e escolha da profissão: no mundo do trabalho atual. São Paulo: Vetor, 2001.

LOPONTE, L. N. A trajetória do jovem estudante do ensino técnico, na opinião dos alunos do Instituto Federal de Educação, Ciência e Tecnologia de São Paulo. In: SIMPÓSıO BRASILEIRO DE POLÍTICA E ADMINISTRAÇÃO DA EDUCAÇÃO. Campinas, 2011. Anais [...]. São Paulo: Unicamp, 2011.

MAGALHÃES, M. O. D.; ALVARENGA, P.; TEIXEIRA, M. A. P. Relação entre estilos parentais, instabilidade de metas e indecisão vocacional em adolecentes. Revista Brasileira de Orientação Profissional, Porto Alegre, v. 13, n. 1, p. 15-25, jun. 2012.

MARQUES, P. B.; CASTANHO, M. I. S. O que é a escola a partir do sentido construído por alunos. Associação Brasileira de Psicologia Escolar e Educacional, Maringá, v. 15, n. 1, p. 23-33, jan./jun. 2011.

MARTINS, D. D. F.; NORONHA, A. P. P. Interesse profissional e características socioeconômicas de estudantes do Ensino Médio. Psico, Porto Alegre, v. 41, n. 1, p. 76-84, jan./mar. 2010.

MATOS, D. A. S.; RODRIGUES, E. C. Análise fatorial. Brasília: Enap, 2019.

NEPOMUCENO, R. F.; WITTER, G. P. Influência da família na decisão profissional: opinião de adolecentes. Psicologia Escolar e Educacional, São Paulo, v. 14, n. 1, p. 15-22, jan./jun. 2010.

NOGUEIRA, M. A. A escolha do estabelecimento de ensino pelas famílias: a ação discreta da riqueza cultural. Revista Brasileira de Educação, Rio de Janeiro, n. 7, p. 42-56, 1998.

PAIM, R. M. O. A escolha profissional sob um olhar psicanalítico. Revista Recrearte, 2007. Disponível em: encurtador.com.br/akS27. Acesso em: 10 maio 2017.

PALLANT, J. SPSS Survival Manual: a step by step guide to data analysis using SPSS for Windows. 3. ed. New York: Open University Press, 2007. 
PEREIRA, F. N.; GARCIA, A. Amizade e escolha profissional: influência ou cooperação? Revista Brasileira de Orientação Profissional, Porto Alegre, v. 8, n. 1, p. 71-86, 2007.

RABELO, A. L. A.; TRÓCCOLI, B. T.; ROCHA, F. E. D. C. Análise fatorial de questionários sobre o uso sustentável da água na agricultura. Documentos - Embrapa Cerrados, 2015. Disponível em: https://ainfo.cnptia.embrapa.br/digital/bitstream/item/141010/1/doc325.pdf. Acesso em: 15 maio 2018.

RAMOS, M. Possibilidades e desafios na organização do currículo integrado. In: FRIGOTTO, G.; RAMOS, M.; CIAVATTA, M. (Org.). Ensino Médio Integrado: concepção e contradições. São Paulo: Cortez, 2005. p. 106-27.

SANTOS, L. M. M. O papel da família e dos pares na escolha profissional. Psicologia em estudo, Maringá, v. 10, n. 1, p. 57-66, jan./abr. 2005.

SANTOS, M. S. C. D.; BRANDÃO, L. E. T.; MAIA, V. M. Decisão de escolha de carreira no Brasil: uma abordagem por opções reais. Revista de Administração, São Paulo, n. 50, p. 141-52, jan. 2015.

SCHAWB, A. J. Eletronic Classroom. The University of Texas at Austin, 2007. Disponivel em: http://www.utexas.edu/ssw/eclassroom/schwab.html. Acesso em: 18 jan. 2019.

SEVERNINI, E.; ORELLANO, V. O efeito do ensino profissionalizante sobre a probabilidade de inserção no mercado de trabalho e sobre a renda no período Pré-Planfor. Texto para discussão n. 268. São Paulo: FGV, 2010.

SOARES, D. H. P. A escolha profissional do jovem ao adulto. São Paulo: Summus, 2002.

TABACHNICK, B. G.; FIDELL, L. S. Using multivariate analysis. California: Harper Collins Publishers, 2007.

VALORE, L. A. A problemática da escolha profissional: a possibilidade e compromissos da ação psicológica. Scielo Book, 2008. Disponível em: http://books.scielo.org/id/hn3q6/ pdf/silveira-9788599662885-07.pdf. Acesso em: 10 dez. 2018.

WATARAI, F.; ROMANELLI, G. Escolarização de adolecentes do sexo masculino das camadas populares. In: CUNHA, M. V.; PASIAN, S. R.; ROMANELLI, G. (Org.). Pesquisa em psicologia: múltiplas abordagens. São Paulo: Vetor, 2009. p. 205-32.

ZELLER, R. A.; CARMINES, E. G. Measurement in the Social Sciences: the link between theory and data. Nova lorque: Cambridge University Press, 1980. 


\section{Sobre os autores:}

Nonato Assis de Miranda: Doutorado em Educação pela Universidade Estadual de Campinas. Coordenador do Programa de Pós-Graduação em Educação - Mestrado Profissional em Educação da Universidade Municipal de São Caetano do Sul (Uscs) e coordenador-geral do Curso de Pedagogia da Universidade Paulista (Unip). E-mail: mirandanonato@uol.com.br, Orcid: http://orcid.org/0000-0001-6592-3381

Piagetti Júnior Pires Arcy: Mestrado em Educação pela Universidade Municipal de São Caetano do Sul (Uscs). Pós-graduação em Administração Industrial pela Fundação Vanzolini / USP. Administração Gerencial pela Faculdade de Economia, Administração e Contabilidade da Universidade de São Paulo (FEA-USP). Engenheiro mecânico pela Universidade de Mogi das Cruzes (UMC). Professor da Etec Jorge Street (SCS-Ceeteps). E-mail: arcy.junior@etec.sp.gov.br, Orcid: http://orcid.org/0000-0002-9768-5653

Recebido em: 4 de agosto de 2019 Última revisão: 20 de maio de 2020 Aprovado em: 28 de julho de 2020 
